\title{
Pestisida Organoklorin dalam Sedimen di Muara Sungai Upang, Provinsi Sumatera Selatan
}

\author{
Ria Ariana, Gusti Diansyah, Wike Ayu Eka Putri* \\ Program Studi Ilmu Kelautan, Fakultas Matematika dan Ilmu Pengetahuan Alam, Universitas Sriwijaya \\ Jl. Raya Palembang-Prabumulih Km 32, Inderalaya, Sumatera Selatan 30662 \\ Email : wike.aep@gmail.com
}

\begin{abstract}
Abstrak
Pestisida adalah substansi kimia yang bersifat akumulatif dalam sedimen. Tujuan dari penelitian adalah untuk mengetahui jenis dan konsentrasi pestisida organoklorin yang terakumulasi di sedimen Muara Sungai Upang. Pengambilan sampel dilaksanakan pada bulan September 2017 di Sungai Upang hingga ke muara. Analisis sampel menggunakan metode Gas Chromatography Mass Spectrometry. Hasil penelitian menemukan pestisida organoklorin terakumulasi di dua stasiun yaitu stasiun 2 dan stasiun 5. Jenis pestisida organoklorin yang ditemukan adalah Endrin dengan konsentrasi $0,35 \mathrm{ppb}$ pada stasiun 2 dan $0,41 \mathrm{ppb}$ pada stasiun 5. Konsentrasi endrin yang ditemukan pada kedua stasiun tersebut telah melewati batas mutu yang diperkenankan $(0,0624 \mathrm{ppb})$.
\end{abstract}

Kata Kunci : Estuari, Organoklorin, Pestisida, Sedimen, Upang

Abstract

\section{Organochlorine Pesticides From Upang Estuary Sediment, South Sumatera Province}

Pesticides are chemical substancepotentially accumulated in sediment. The purpose of this study was to determine the type and concentration of organochlorine pesticides which are accumulated in the sediments Upang Estuary. Sampling was conducted in September 2017 along Upang River to estuary. Analysis of pesticides using Gas Chromatography Mass Spectrometry. The result of the research was obtained that organochlorine pesticides accumulated in station 2 and station 5. Type of organochlorine pesticides found was Endrin of $0.35 \mathrm{ppb}$ in station 2 and $0.41 \mathrm{ppb}$ in station 5. Endrin concentration found at both stations has passed the quality threshold (0.0624 ppb).

Keywords: Estuary, Organochlorine, Pesticide, Sediment, Upang

\section{PENDAHULUAN}

Pestisida berasal dari kata pest yang berarti hama dan cida ang berarti pembunuhan. Pestisida adalah substansi kimia yang digunakan untuk membunuh atau mengendalikan berbagai hama (Yuantari, 2011). Penggunaan pestisida dalam pertanian dan perkebunan telah banyak membantu untuk meningkatkan jumlah produksi pertanian dengan membunuh dan menghambat hama penggangu yang dapat merusak tanaman. Namun disisi lain penggunaan pestisida ini juga dapat mencemari lingkungan seperti air, tanah dan udara.

Salah satu jenis pestisida yang berbahaya adalah pestisida dari golongan organoklorin. Menurut Sembel (2015) pestisida dari golongan ini merupakan salah satu bahan pencemar yang tidak dapat diuraikan secara hayati (non biodegradable) sehingga cenderung tinggal dalam lingkungan cukup lama. Selain itu kemungkinan untuk mengalami bioakumulasi dan biomagnifikasi dalam lingkungan juga besar. Pestisida organoklorin dalam konsentrasi tertentu dapat bersifat estrogenik yaitu dapat mengganggu atau mencegah kinerja hormon estrogen alami pada manusia.Selain itu pestisida organoklorin juga merupakan salah satu seyawa yang bersifat karsinogenik (Edward, 2016).

Penelitian tentang konsentrasi organoklorin telah dilakukan di beberapa derah di Indonesia misalnya di Teluk Jakarta. Ada dua penelitian yang dilakukan dalam waktu yang berbeda (Munawir, 2005; Pratoton et al., 2009). Kedua penelitian ditemukan pestisida jenis organoklorin di daerah tersebut dengan konsentrasi yang terus meningkat, yaitu pada air dan sedimen juga ditemukan dalam kerang hijau di Teluk Jakarta. Kandungan pestisida organokhlorin dalam kerang hijau di Teluk Jakarta relatif tinggi, namun masih aman untuk dikonsumsi (Edward, 2016) 
Beberapa penelitan serupa juga telah dilakukan di beberapa muara sungai yang ada di Sumatera yaitu di Muara Sungai Siak, Riau (Munawir, 1996); Muara Kuala Jambi dan Kuala Tungkal , Jambi (Munawir, 1997); danMuara Sungai Musi, Palembang (Munawir, 1998). Hasil penelitian menunjukkan bahwa pestisida organoklorin terkonsentrasi dalam sedimen lebih rendah jika dibandingkan dengan baku mutu yang ditetapkan untuk perairan laut.

Aliran Sungai Musi bermuara di Muara Sungsang, Muara Sungai Upang dan Muara Saleh. Penelitian penentuan kadar residu pestisida sebelumnya telah dilakukan oleh Munawir (1998) di daerah Muara Sungsang, sedangkan di Muara Sungai Upang sendiri belum pernah dilakukan penelitian tersebut. Muara Sungai Upang juga berpotensi tercemar residu pestisida karena aktivitas pertanian dan perkebunan juga dijumpai disepanjang aliran Sungai Musi. Penelitian ini bertujuan untuk mengetahui konsentrasi pestisida organoklorin di perairan Muara Sungai Upang Provinsi Sumatera Selatan (Affandi dan Heron, 2012). Organoklorin yang dicari adalah DDT (dicloro diphenyl trichloroethane), Endrin, Dieldrin, Aldrin, Endosulfan dan Klordan. DDT memiliki karakteristik yang tahan lama di lingkungan, karsinogenik, danakumulatif (Prartono, 2009). Endosulfan bersifat non sistematik serta bertindak sebagai racun kontak dan racun perut (Yuantari, 2011).

\section{MATERI DAN METODE}

Daerah penelitian dibagi menjadi tujuh stasiun (Gambar 1). Stasiun 1 terletak dibagian sebelum percabangan Muara Sungsang dan Muara Sungai Upang. Stasiun 2 terletak dibagian pangkal Sungai Upang. Stasiun 3 terletak di bagian dalam sungai yang mengarah kemuara. Stasiun 4, 5, 6, dan7 terletak disekitar Muara Sungai Upang. Analisis pestisida mengunakan Gas Chromatography Mass Spectrometry Thermo Scientific Trace GC Ultra di Balai Besar Laboratorium Kesehatan Palembang.

Sedimen diambil menggunakan Ekman grab dari bahan stainless steel. Sampel sedimen kemudian dimasukkan kedalam botol kaca yang telah di bersihkan. Botol kaca dilapisi aluminium foil kemudian ditutup rapat untuk menghindari kontaminasi. Selanjutnya dimasukkan kedalam cool box dengan suhu di bawah $4^{0} \mathrm{C}$ Selama transportasi menuju laboratorium (APHA, 2005).

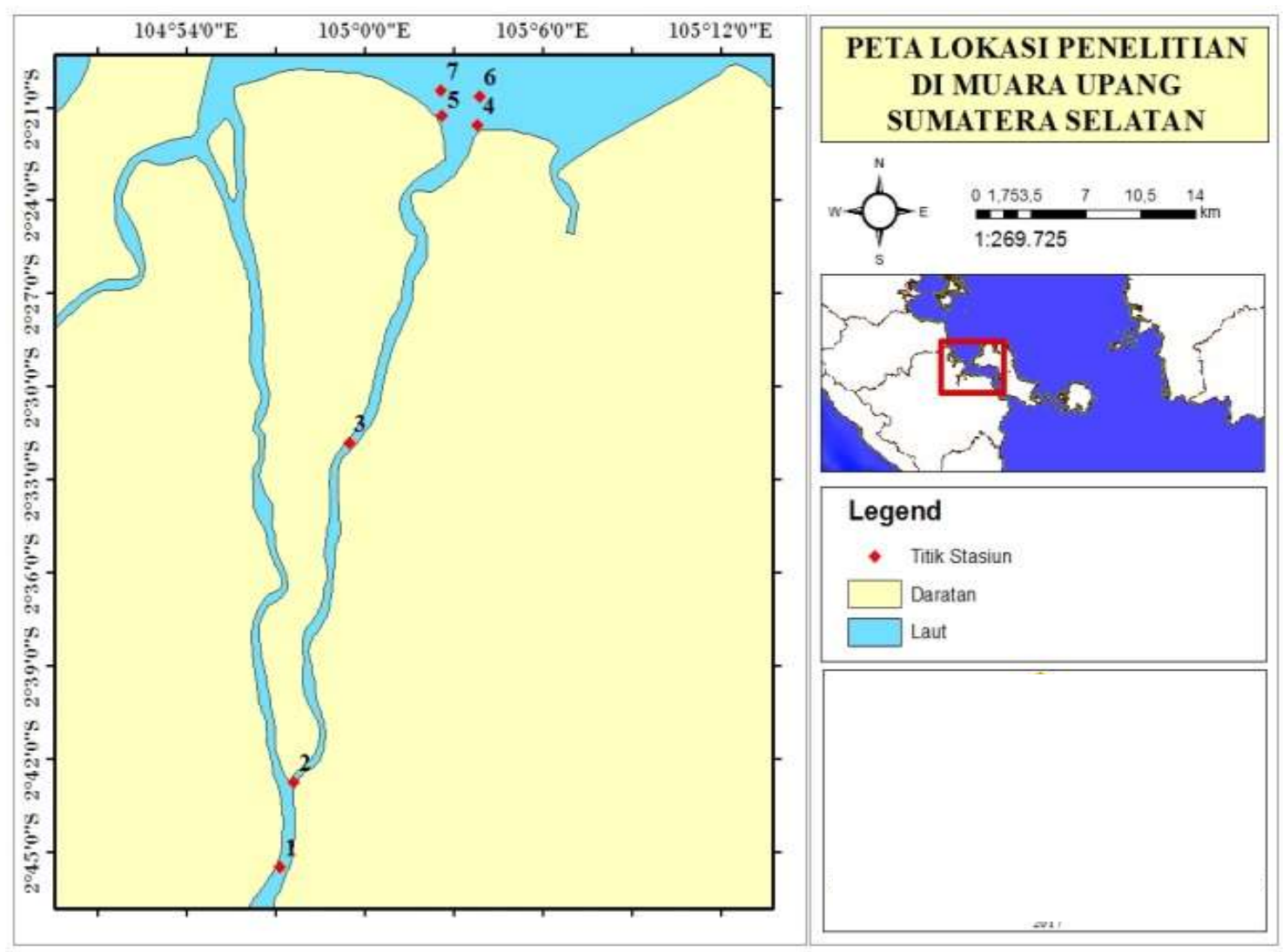

Gambar 1. Peta lokasi penelitian 
Sampel sedimen dikeringkan dengan cara didiamkan pada suhu ruangan selama kuranglebih 48 jam tanpa menggunakan oven. Sampel kering ditimbang sebanyak 10 gr lalu ditambahkan Chlorophyrifos. Kemudian sampel dilarutkan kedalam pelarut Aseton dan N-hexane sebanyak $50 \mathrm{ml}$ dengan perbandingan 1:1. Sampel diaduk selama kurang lebih 10 menit hingga larut. Corong dan glass woll disiapkan kemudian ditambahkan $\mathrm{Na}_{2} \mathrm{SO}_{4}$ anhidrat pada glass woll. Lalu sampel disaring. Hasil penyaringan diambil kemudian dilarutkan kembali dengan Aseton dan $\mathrm{N}$-hexane dan disaring kembali untuk mendapatkan hasil yang optimal. Setelah disaring dilakukan ekstraksi dengan menggunakan gas nitrogen agar pelarut dapat terpisah, hingga mencapai volume $2 \mathrm{ml}$.

Berdasarkan SNI 06-6990.1-2004, pengoperasian GC diatur pada suhu bertahap yaitu $70^{\circ} \mathrm{C}$ untuk 2 menit awal kemudian naik menjadi $130^{\circ} \mathrm{C}$ dengan laju kenaikan $20^{\circ} \mathrm{C}$ per menit (diamkan selama 4 menit) kemudian temperature dinaikkan kembali menjadi $200^{\circ} \mathrm{C}$ dengan kenaikan suhu $5^{\circ} \mathrm{C}$ per menit dan naik lagi menjadi $300^{\circ} \mathrm{C}$ dengan kenaikan suhu $15^{\circ} \mathrm{C}$ per menit (didiamkan selama \pm 5 menit). Suhu injeksi dan detekor adalah pada $280^{\circ} \mathrm{C}$. Kemudian sampel dimasukan ke dalam injeksi sebanyak $1 \mu \mathrm{L}$. Kadar masing-masing pestisida organoklorin per volume contoh uji kemudian dihitung dengan rumus(SNI 06-6990.1-2004).

Data hasil perhitungan akan diplotkan dalam bentuk table kemudian dibahas secara deskriptif, selanjutnya akan dibandingkan dengan baku mutu yang ada (Canadian Sediment. Quality Guidelines for the Protection of Aquatic Life).

\section{HASIL DAN PEMBAHASAN}

Hasil analisis kandungan pestisida organoklorin menggunakan GC-MS dapat dilihat pada Tabel 1, dimana diperoleh 2 stasiun (stasiun 2 dan stasiun 5) yang positif mengandung pestisida organoklorin. Jenis pestisida organoklorin yang ditemukan adalah Endrin dengan konsentrasi masing-masing yaitu $0,35 \mathrm{ppb}$ dan 0,41 ppb. Berdasarkan CCME (2001) konsentrasi endrin pada Stasiun 2 dan Stasiun 5 telah melewati ambang batas yang diperbolehkan yaitu $0,0624 \mathrm{ppb}$.

Endrin digunakan sebagai salah satu pestisida untuk membasmi serangga maupun binatang pengerat. Penggunaan endrin sudah dilarang dibanyak Negara salah satunya adalah
Indonesia. Seperti pestisida organoklorin lainnya, endrin cenderung mudah terakumulasi dalam jaringan lemak. Karakterisitk endrin adalah memiliki titik lebur $200^{\circ} \mathrm{C}$, titik didih $245^{\circ} \mathrm{C}$, dan kadar kelarutan endrin dalam air adalah sebesar 220-260 $\mu \mathrm{g} / \mathrm{L}$. Waktu paruh endrin dalam tanah diperkirakan sekitar 14 tahun dan bersifat kurang persisten dibandingkan dieldrin. Endrin akan bersifat racun jika tertelan dengan kadar mencapai 7,5 ppm dalam makanan dan tidak berpotensi menimbulkan kanker pada manusia tetapi dapat mengganggu system syaraf (Edward, 2016).

Sedimen dengan jenis clay atau lempung dapat mempertahankan residu pestisida dalam jumlah yang lebih banyak dari pada pasir berlumpur atau pasir berlempung (Nerm et al., 2012). Berbeda dengan penelitian yang didapat di Muara Sungai Upang dimana endrin ditemukan pada Stasiun 2 yang merupakan stasiun dengan jenis sedimen pasir. Hal ini diduga karena adanya aktifitas pengerukan pasir pada daerah stasiun 2 yang dilakukan secara terus-menerus hingga sekarang. Diduga pestisida organoklorin yang telah mengendap pada lapisan dalam sedimen dan tertimbun oleh lapisan sedimen yang baru akan berada di lapisan permukaan sedimen kembali karena proses pengerukan tersebut sehingga di stasiun 2 ditemukan pestisida organoklorin.

Penelitian dan pemantauan tentang organoklorin dalam sedimen telah banyak dilakukan di dunia. Penelitian kontaminasi dan penilaian resiko organoklorin di permukaan sedimen pantai Mediterania (Mesir) oleh Nemr et al. (2012) menemukan konsentrasi endrin berkisar antara 0,004- 0,19 $\mu \mathrm{g} / \mathrm{g}$. Barakat et al. (2002) juga telah melakukan penelitian di Pelabuhan Alexandria (Mesir) dan menemukan konsentrasi pestisida $0,1-6,7 \mu \mathrm{g} / \mathrm{g}$. Pestisida organoklorin termasuk endrin telah dilarang di banyak negara tetapi konsentrasi endrin yang ditemukan masih diatas baku mutu.

Indonesia telah melarang penggunaan pestisida organoklorin sejak tahun 2001 berdasarkan Konvensi Stockholm dan Peraturan Pemerintah RI No. 74 Tahun 2001. Terdapat dugaan bahwa pestisida yang ditemukan merupakan sisa-sisa residu yang telah ada, sehingga tidak pada setiap stasiun ditemukan pestisida organoklorin. Berdasarkan CCME (1999), endrin akan terdegradasi secara lebih lambat dalam sedimen perairan, sehingga jika sumber pencemar pestisida endrin berkurang maka konsentrasinya juga akan berkurang dari waktu ke waktu. 
Tabel 1. Konsentrasi Pestisida di Muara Sungai Upang (ppb)

\begin{tabular}{lccccccc}
\hline \multirow{2}{*}{ Jenis Pestisida } & \multicolumn{7}{c}{ Stasiun } \\
\cline { 2 - 8 } \multicolumn{1}{c}{} & 1 & 2 & 3 & 4 & 5 & 6 & 7 \\
\hline DDT & - & - & - & - & - & - & - \\
Endrin & - & 0,35 & - & - & 0.41 & - & - \\
Dieldrin & - & - & - & - & - & - & - \\
Aldrin & - & - & - & - & - & - & - \\
Endosulfan & - & - & - & - & - & - & - \\
Klordan & - & - & - & - & - & - & - \\
\hline
\end{tabular}

\section{KESIMPULAN}

Berdasarkan penelitian yang telah dilakukan di Muara Sungai Upang pestisida organoklorin ditemukan pada stasiun 2 dan stasiun 5 dengan nilai yang telah melewati ambang batas. Pestisida yang terkandung pada stasiun 2 dan stasiun 5 adalah pestisida organoklorin dari jenis Endrin.

\section{DAFTAR PUSTAKA}

Affandi A.K \& Heron S. 2012.Distribusi sedimen di perairan pesisir Banyuasin, Sumatera Selatan. Maspari Journal 4(1):33-39

[APHA] American Public Health Association. 2005. Standart Method for the Examination of Water and Wastewater. $21^{\text {st }}$ ed. Washingtong DC : APHA.

Barakat, A.O., Kim, M., Qian, Y. \& Wade, T.L., 2002. Organochlorine pesticides and PCB residues in sediments of Alexandria Harbour, Egypt. Marine Pollution Bulletin, 44(12), pp.1426-1434.

[CCME] Canadian Council of Ministers of the Environment. 2001. Canadian Sediment. Quality Guidelines for the Protection of Aquatic Life. Excerpt from Publication No. 1299; ISBN 1-896997-34-1.

Edward, 2016. Bioakumulasi senyawa organoklorin (POC) dalam kerang hijau (Perna viridis) di Teluk Jakarta. Jurnal Ilmu dan Teknologi Kelautan Tropis 8(1):85-97

Munawir, K. 1996. Pemantauan Kadar Pestisida Organoklorin di Perairan Muara Sungai Siak, Riau. Jakarta :Puslitbang Oseanologi - LIPI

1997. Kadar pestisidaorganoklorin di perairan Muara Sungai Kuala Tungkal, Jambi. Jakarta :Puslitbang Oseanologi LIPI
. 1998. Kadar Pestisida Organoklorin di Perairan Muara Sungai Musi Palembang. Jakarta : Puslitbang Oseanologi - LIPI.

2005. Pemantauan kadar pestisida organoklorin di beberapa muara sungai di perairan Teluk Jakarta. Oseanografi dan Limnologi di Indonesia, 37:15-25..

Nemr, A.E., Abeer, A.M., Azza, K., \& Amany E.S. 2012. Contamination and risk assessment of organochlorines in surface sediments of Egyptian Mediterranean coast. Egyptian Journal of Aquatic Research, 38:7 -21 .

Peraturan Pemerintah RI No. 74 Tahun 2001. Pengolahan Bahan Berbahaya dan Beracun. Jakarta : Presiden Republik Indonesia.

Prartono, T., Razak, H. \& Gunawan, I. 2009. Pestisida organoklorine di sedimen pesisir muara Citarum, Teluk Jakarta : peran penting fraksi halus sedimen sebagai pentransport DDT dan proses diagenesanya. E-Jurnal Ilmu dan Teknologi Kelautan Tropis, 1(2):12-21.

Sembel, D.T. 2015. Toksikologi Lingkungan. Manado :Penerbit Andi.

[SNI] Standar Nasional Indonesia. 2004. AirBagian 1 : Cara Uji Pestisida Organoklorin Secara Ekstraksi Menggunakan Pelarut n-Heksan dengan Kromatografi Gas-Spektrofotometer Massa $(K G-M S)$. Jakarta : Badan Standardisasi Nasional.

Yuantari, C. 2011. Dampak pestisida organoklorin terhadap kesehatan manusia dan lingkungan serta penanggunalangannya. Di dalam : Peran Kesehatan Masyarakat dalam Pencapaian MDG's of Indonesia. Prosiding Seminar Nasional. 187-199 hlm. 